\title{
Comparison of Blood Gas Analysis between Benchtop and Handheld Device
}

\author{
Phey Liana ${ }^{1}$, Iza Netiasa Haris ${ }^{2}$, Yan Effendi Hasyim³ \\ ${ }^{1}$ Department of Clinical Pathology, Faculty of Medicine, Sriwijaya University/Dr. Mohammad Hoesin General Hospital, Palembang, \\ Indonesia. E-mail: pheyliana@yahoo.com \\ ${ }^{2}$ Faculty of Medicine, Sriwijaya University, Palembang, Indonesia \\ ${ }^{3}$ Department of Histology, Faculty of Medicine, Sriwijaya University, Palembang, Indonesia
}

\begin{abstract}
The use of blood gas analysis is to determine the Acid-base status required to treat patients with emergency conditions such as metabolic disorders and respiratory diseases. Benchtop device is commonly used in hospitals to analyze blood gas; however, handheld devices are recently more often used in emergency settings due to its quick and simple process. This study was performed to compare blood gas analysis results between the i-STAT handheld device and the Nova pHox Ultra benchtop device that were currently being used in the central laboratory. This cross-sectional study was conducted by using 42 arterial blood patients that were measured with i-STAT handheld device dan Nova pHox Ultra benchtop device. The pH, pCO2, and $\mathrm{pO} 2$ parameters were then evaluated. The data were analyzed using Spearman's correlation test, Mann-Whitney test, and Bland-Altman plots. This study showed a very strong positive correlation for all parameters. Mann-Whitney comparison test showed that there was no significant difference between the result of the two devices $(p$-value $>0.05)$. All parameters showed that $95 \%$ of plots were within the acceptable limit. There was no clinical significance on the mean biases of blood gas results between both devices. The i-STAT and Nova pHox Ultra devices showed a good agreement for blood gas measurement. Therefore, both devices can be used interchangeably with minimal effect on clinical decision-making.
\end{abstract}

Keywords: Blood gas analysis, benchtop device, handheld device

\section{INTRODUCTION}

Acid-base balance is important to the human body. Acid-base balance refers to the accurate regulation of free hydrogen ions in body fluid. ${ }^{1}$ Blood gas analysis provides information on the status of oxygenation, ventilation, and acid-base in the patient's body. Components measured in blood gas analysis are $\mathrm{pH}, \mathrm{pCO} 2$, bicarbonate ions ( $\mathrm{HCO} 3-)$, $\mathrm{pO} 2$, base excess, and oxygen saturation. ${ }^{2}$ Blood gas analysis uses arterial blood samples because $\mathrm{pCO} 2$ in arterial blood can represent the component of respiration in the patient's acid-base status. Blood gas analysis is often carried out in laboratories. ${ }^{2}$ Blood gas analysis can be faster performed if a handheld or Point-of-Care (POC) device is used. However, a handheld device allows blood gas analysis to be carried out more closely with the patient. Analysis can be performed in the same room without having to bring the specimen to the laboratory. ${ }^{3}$

Decision-making and management are more quickly because the results of the test are immediately analyzed. ${ }^{3}$ Trained health workers can also perform the analysis using handheld devices in addition to laboratory personnel. Handheld devices are smaller than blood gas analyzers that are commonly available in the laboratory, making them more practical to use anywhere. Therefore, the response of therapy is easy to be monitored. ${ }^{4}$

Blood gas analysis performs by using handheld and benchtop devices. I-STAT handheld device is used in the intensive care unit, while the Nova pHox Ultra benchtop device is used in the central laboratory. A comparison test is needed to evaluate the compatibility of the results between I-STAT and Nova pHox Ultra devices. Therefore, this study aimed to determine the agreement of the results of both devices. If the results are compatible, those devices can be used interchangeably for monitoring a patient's progress.

\section{METHODS}

This study was an analytical observational study with a cross-sectional design. The research was performed in the Clinical Pathology Laboratory of Dr. Mohammad Hoesin Hospital Palembang in October 
and November 2019. Samples of the study were the patient's arterial blood that was sent for blood gas analysis to the central laboratory. A total of 42 arterial blood samples were examined with Abbott i-STAT handheld POC device and Nova pHox Ultra benchtop device. According to the Clinical Laboratory Standards Institute (CLSI) guidelines, a minimum of 40 samples are needed for method comparison study (NCCLS document EP9-A2). ${ }^{5}$

Arterial blood samples from patients were formerly measured with Nova pHox Ultra and immediately with Abbott i-STAT afterward with a time difference of fewer than 10 minutes. CG4+ disposable cartridges $03 \mathrm{P} 85-50$ by Abbott point of care, USA on Abbott i-STAT and Stat Profile pHOx Ultra cartridges 488831 by Nova Biomedical, USA were used. The parameters evaluated in this study were $\mathrm{pH}, \mathrm{pCO} 2$, and pO2. Data were analyzed using SPSS and MedCalc. The correlation of the results from both devices was determined by the Spearman correlation coefficient. A comparison between both devices was analyzed with the Mann-Whitney test and the BlandAltman agreement test. The research was approved by the Health Research Ethics Committee of the
Faculty of Medicine, Sriwijaya University and Dr. Mohammad Hoesin Central General Hospital (number 446/kepkrsmhfkunsri/2019).

\section{RESULTS AND DISCUSSION}

Table 1 showed the results of blood gas analysis using the Nova pHox Ultra and i-STAT. This study found significant strong correlation coefficients ( $r$ ) between Nova pHOx Ultra and Abbott i-STAT for all parameters that were examined $(r>0.8)$. This result was consistent with several previous studies. In research conducted by Indrasari et al. using i-STAT and Nova pHox Plus $L$ with a total of 100 samples, the correlation test showed the value of $p<0.05$ and $r>0.8$ for the parameters of $\mathrm{pH}, \mathrm{pCO} 2$, and $\mathrm{pO} 2$. This analysis showed a strong correlation in the results of blood gas analysis between the POCT device and laboratory blood gas analyzer. ${ }^{6}$ A study conducted by Lukkonen et al. using the POCT EPOC device with the Rapidlab RL1265 laboratory device and the RP500 Rapid point, the correlation test showed results of $\mathrm{p}<0.001$ for $\mathrm{pH}, \mathrm{pCO} 2$, and $\mathrm{pO} 2$ parameters. ${ }^{\top}$

Table 1. Blood gas analysis results of both devices

\begin{tabular}{|c|c|c|c|c|}
\hline Parameters & $\begin{array}{c}\text { Nova pHOx Ultra } \\
(n=42)\end{array}$ & $\begin{array}{c}\text { Abbott i-STAT } \\
(n=42)\end{array}$ & R; p-value ${ }^{a}$ & p-value ${ }^{b}$ \\
\hline $\mathrm{pH}$ & $7.388(7.001-7.502)$ & $7.382(6.944-7.522)$ & $0.935 ; 0.000$ & 0.854 \\
\hline $\mathrm{pCO} 2$ & $36.6(13.8-115.7)$ & $40.4(13.2-109.9)$ & $0.955 ; 0.000$ & 0.285 \\
\hline pO2 & $105.3(33.0-295.4)$ & $111.0(27.0-260.0)$ & $0.944 ; 0.000$ & 0.929 \\
\hline
\end{tabular}

${ }^{a}$ Spearman test ${ }^{b}$ Mann-Whitney test

Table 2. Bland-Altman agreement test results of arterial blood gas analysis between Abbott i-STAT and Nova pHox Ultra

\begin{tabular}{ccccc}
\hline Parameters & $\begin{array}{c}\text { Mean } \\
\text { Difference }\end{array}$ & $\begin{array}{c}\text { Limit of } \\
\text { Agreement }\end{array}$ & $\begin{array}{c}\text { Concordance } \\
\text { Correlation Coefficient }\end{array}$ & Regression Equation \\
\hline $\mathrm{pH}$ & 0.02 & $(-0.08)-(0.11)$ & 0.9249 & $\mathrm{y}=-1,693886+1,228790 \mathrm{x}$ \\
$\mathrm{pCO} 2$ & -2.5 & $(-12.2)-(7.2)$ & 0.9500 & $\mathrm{y}=-1,73889+1,111111 \mathrm{x}$ \\
$\mathrm{pO}_{2}$ & 4.8 & $(-35.6)-(45.3)$ & 0.9337 & $\mathrm{y}=-2,793478+0,978261 \mathrm{x}$ \\
\hline
\end{tabular}

(a)

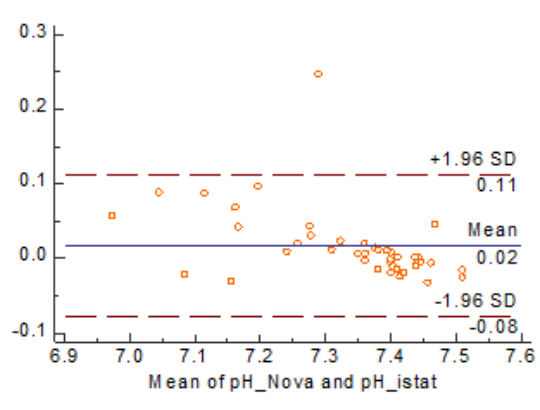

(b)

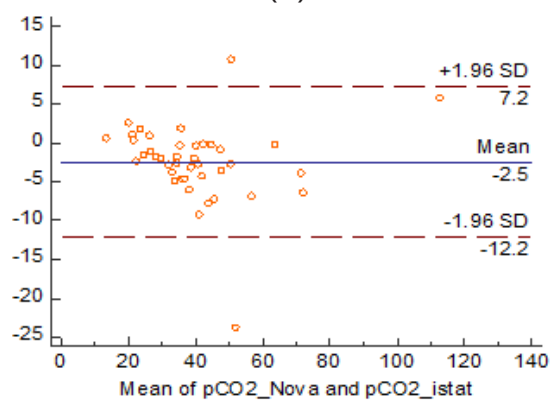

(c)

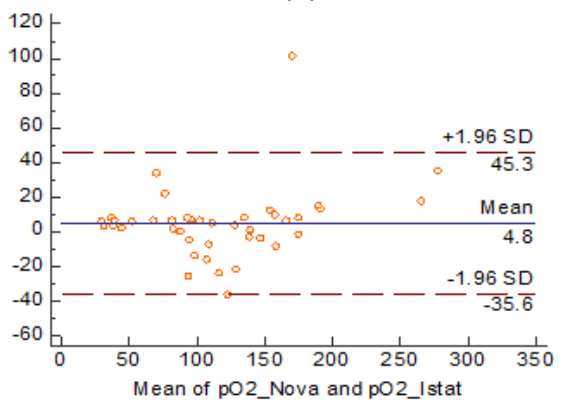

Figure 1. Bland-Altman plots (a) $\mathrm{pH}$; (b) pCO2; (c) pO2 
Strong correlation coefficient (R2) value between the EPOC POCT device and RL1265 Rapidlab laboratory instrument and between the EPOC POCT device and RP500 Rapid point laboratory instrument were observed for $\mathrm{pH}, \mathrm{pCO} 2$, and $\mathrm{pO} 2$ parameters. ${ }^{7}$ Plathe found a good correlation between results of POCT i-STAT and blood gas analyzer 288 laboratories with $\mathrm{R}$ values $>0.8$ for parameters $\mathrm{pH}$, $\mathrm{pCO} 2$, and $\mathrm{pO} 2 .{ }^{\circ}$

A comparative test showed $p$-value $>0.05$ for all parameters $(\mathrm{pH}, \mathrm{pCO} 2$, and $\mathrm{pO} 2)$, indicating that there was no significant difference between the results of i-STAT and pHox Ultra. These results were consistent with the results of the Spearman correlation test.

The results of the Bland-Altman test for $\mathrm{pH}$ parameters showed that $97.6 \%$ of blood gas analysis results were within the acceptance limit of -0.08 to 0.11 with a mean bias of 0.02 . The study also found that $95.2 \%$ of the results of the blood gas analysis for pCO2 were within the acceptance limit of -12.2 to 7.2 , with an average bias of -2.5 . In addition, for the $\mathrm{O} 2$ parameter, the data showed that $97.6 \%$ of the results were within the acceptance limit of -035.6 to 45.3 with a mean bias of 4.8 .

This study showed that $>95 \%$ of the plots were within the range of acceptable limits for all three parameters. This result was consistent with research conducted by Indrasari et al. ${ }^{6}$ That study found an agreement between the results measured with i-STAT and Nova pHox Plus L with $96 \%$ of the results of $\mathrm{pH}$ tests were still within the acceptance limit, and $95 \%$ of the $\mathrm{pCO} 2$ and $\mathrm{pO} 2$ examination results were still within the acceptance limit. ${ }^{6}$ Another study conducted by Gray et al., which compared POCT i-STAT and ABL 500 meters using rat blood samples, showed that $>95 \%$ of the samples were within the range of acceptance. ${ }^{9}$

Centers for Disease Control and Prevention (CDC) has made a regulation called Clinical Laboratory Improvement Amendments (CLIA); one of the objectives of the regulation is to monitor the quality of the laboratory test results by setting limits or the target value standards of the test results. The standards-based on CLIA 1988 were compared with the results of the analysis in this study. Acceptance between handheld and benchtop equipment was evaluated from the average bias results of blood gas analysis between handheld and benchtop equipment. The average bias of 0.02 was obtained for $\mathrm{pH}$ (target value \pm 0.04 ), $-2.5 \mathrm{mmHg}$ for $\mathrm{pCO} 2$ (target value $\pm 5 \mathrm{mmHg}$ or $\pm 8 \%$ ), and $4.8 \mathrm{mmHg}$ for pO2 (target value \pm 3 SD, SD: 20,626). The results showed that all of the average bias was still within the accepted standards in the CLIA 1988, indicating that the results of the measurement results of the two devices can be used alternately. ${ }^{10}$

Blood gas analysis is a laboratory test to identify changes in the status of acid-base and oxygenation. This test was often performed at the ICU and emergency. Precise and accurate results are expected in this test. Measurement using benchtop laboratory equipment requires a longer time because operation must be based on the existing procedures. Point-of-care testing devices are one of the devices that are relied upon to get fast results. However, this device can not be used continuously because it requires more costs. The analysis in this study was conducted to determine the possibility that both methods could be used interchangeably. ${ }^{2-4}$

A comparative test was performed to evaluate the mean difference between both methods. However, this analysis merely gave little information about the accuracy of the method. Consequently, the mean difference test is not commonly used for the comparison of measurement methods. ${ }^{11}$

Correlation test analysis is often used for comparative study. Correlation analysis can be used to determine the linear relationship between two methods but not the acceptance of the device. Agreement test analysis is considered appropriate to determine acceptance because the analysis is carried out by considering the data distribution of each test result. ${ }^{11}$

\section{CONCLUSION AND SUGGESTION}

Differences in the results of blood gas analysis between i-STAT handheld and Nova pHox Ultra benchtop devices can be neglected; therefore, both devices can be used interchangeably for analyzing the patient's blood gas. Both devices can also be replaced by each other with minimal error and effect in clinical decision making. It was suggested to perform an agreement test by comparing two laboratory devices for clinical use to assess clinical difference or significance of results between both devices.

\section{REFERENCES}

1. Sherwood L. Keseimbangan asam basa. In: Fisiologi manusia dari sel ke sistem. $8^{\text {th }}$ Ed., Jakarta, EGC, 2013; 584-618.

2. Davis MD, Walsh BK, Sittig SE, Restrepo RD. AARC clinical practice guideline: blood gas analysis and hemoximetry. Respir Care, 2013; 58(10): 1694-703. Available from: http://rc.rcjournal.com/cgi/doi/ 10.4187/respcare.02786 (accessed 11 June, 2019) 
3. Price $C P$, John A St. Point-of-care instrument. In: Burtis $C A$, Bruns $D E$, editors. Tietz fundamental of clinical chemistry and molecular diagnostic. $7^{\text {th }}$ Ed., Missouri, Elsevier Saunders, 2008; 272-84.

4. Price $C$. Medical and economic outcomes of point-ofcare testing. Clin Chem Lab Med, 2002; 40(3): 246-51. Available from: http://ovidsp.ovid.com/ovidweb. c gi ? T = JS \& PAGE = reference \&D = e med $5 \&$ NEWS $=$ N\&AN $=2002149645$ (accessed 22 June, 2019)

5. The National Committee for Clinical Laboratory Standards. Method comparison and bias estimation using patient samples: Approved guideline. $2^{\text {nd }}$ Ed., NCCLS Document EP9-A2. PA: CLSI, 2002; 1-75.

6. Indrasari ND, Wonohutomo JP, Sukartini N. Comparison of point-of-care and central laboratory analyzers for blood gas and lactate measurements. J Clin Lab Anal, 2019; 1-7.

7. Luukkonen AAM, Lehto TM, Hedberg PSM, Vaskivuo TE. Evaluation of a handheld blood gas analyzer for rapid determination of blood gases, electrolytes, and metabolites in intensive care setting. Clin Chem Lab Med, 2016; 54(4): 585-94.

8. Muller-Plathe O, Ginzbourg J, Rudolph S. Evaluation of the i-STAT portable blood gas and electrolyte analyzer. J Lab Med, 1997; 21(6): 325-31.

9. Gray TE. Determination of agreement between laboratory instrument. Am Assoc Anim Lab Sci. 1999;38(2):56-9. Available from: https://www. ingentaconnect.com/contentone/aalas/jaalas/1999/0 0000038/00000002/art00005 ?crawler $=$ true \& mimetype $=$ app lication/pdf (accessed 5 December, 2019)

10. Westgard J. CLIA requirements for analytical quality. 2019. Available from: http://www.westgard.com/ clia.htm (accesed 25 December, 2019).

11. Altman DG, Bland JM. Measurement in medicine: The analysis of method comparison studies. Stat, 1983; 32(3): 307. Available from: https://www.jstor.org/ stable/2987937?ori gin=crossref (accesed 5 December, 2019) 